\title{
Population status, distribution and conservation needs of the Endangered Mangshan pit viper Protobothrops mangshanensis of China
}

\author{
Shi-Ping Gong, Dao-De Yang, Yuan-hui Chen, Michael Lau and Fu-Min Wang
}

\begin{abstract}
The Endangered Mangshan pit viper Protobothrops mangshanensis is endemic to the Nanling Mountain Range of China. It has been targeted for exploitation to satisfy the international pet trade and zoological collections since it was described. Long-term intensive exploitation and habitat destruction have resulted in drastic reductions in wild populations, pushing this rare species towards extinction. Since 1990 only limited investigations have been conducted and the most optimistic estimation of the population size was 300-500 individuals, in 2000. Since then, however, there have been no updates on the population status of this snake in the wild. To provide baseline data for effective conservation of this species we conducted a study of its status and distribution, during 2007-2010. Only eight individuals were found during fieldwork and we documented the illegal harvesting of $>30$. The total population of the species was estimated to be 462 , occupying c. $105 \mathrm{~km}^{2}$ in the Nanling Mountain Range. The black market price of a Mangshan pit viper is currently $>$ USD $1,000 \mathrm{~kg}^{-1}$ and illegal trade has led to over-harvesting, which is the greatest threat to the species. Our study indicates that protected areas cannot effectively protect this pit viper if the trade in this species cannot be controlled. Based on the results of our study we present five recommendations for conservation of the species.
\end{abstract}

Keywords China, conservation, distribution, Mangshan pit viper, Nanling Mountain Range, Protobothrops mangshanensis

SHI-PING GoNG (Corresponding author) Guangdong Provincial Public Laboratory for Wild Animal Conservation and Management, Guangdong Entomological Institute (South China Institute of Endangered Animals), No. 105, Xin Gang Road West, Guangzhou 510260, China.

E-mail gsp621@163.com

DAO-DE YANG Institute of Wildlife Conservation, Central South University of Forestry and Technology, Changsha, Hunan, China

YUAN-HUI CHEN Mangshan Nature Museum, Mangshan National Nature Reserve, Yizhang, Hunan, China

Michael Lau Kadoorie Farm and Botanic Garden, Hong Kong, China

FU-MIN WANG Guangdong Provincial Wildlife Rescue Centre, Guangzhou, China

Received 13 January 2011. Revision requested 6 April 2011.

Accepted 26 May 2011.

\section{Introduction}

7 he Mangshan pit viper Protobothrops mangshanensis 1 (Zhao \& Chen, 1990) is endemic to the Nanling Mountain Range of China (Zhao, 1998; Chen, 2003). This species was first found on Mangshan Mountain in Hunan Province in 1989 and was originally named Trimeresurus mangshanensis (Zhao \& Chen, 1990) but thereafter underwent several name changes (Zhang, 1993; Gumprecht \& Tillack, 2004; Guo et al., 2007). Because of its size (up to $2 \mathrm{~m}$ long and $2-4 \mathrm{~kg}$ in weight; Chen, 1998) and distinctive coloration (Plate 1), the extreme toxicity of its venom and its rarity this viper has received extensive media coverage in China. Commercial exploitation has caused the market price for the species to soar since its discovery. In illegal markets the cost of a 2-4 kg individual has increased from USD 30 in 1990 to USD 7,000 in 1997 (Chen, 1998). This high commercial value has resulted in extensive collection and, in addition, habitat destruction and human disturbance also threaten the species (Chen, 1998).

The Mangshan pit viper is categorized as Critically Endangered in the China Red Data Book of Endangered Animals (Zhao, 1998) and the China Species Red List (Wang \& Xie, 2004), and as Endangered on the IUCN Red List (Zhou, 2012). Although the species is protected by Mangshan National Nature Reserve and Nanling National Nature Reserve it is still threatened by poaching and habitat destruction within these reserves (Chen, 2003). Intensive exploitation, trade and habitat destruction have resulted in drastic reductions in the wild populations, pushing this rare species towards extinction (Chen, 2002, 2003).

Since the discovery of the Mangshan pit viper only limited surveys have been conducted and the most recent estimate of the population size was 300-500 in an area of c. $100 \mathrm{~km}^{2}$ (Chen, 2003). However, only 17 individuals were observed during 1990-2000, of which three were in the field and 14 in restaurants, illegal markets and villages (Chen, 2003). For effective conservation of this rare pit viper recent quantitative data on population status, distribution and threats are needed for evaluation of the impact of human activities. During 2007-2010 we therefore conducted the study reported here.

\section{Study area}

The Nanling Mountain Range has a subtropical humid monsoon climate typical of the region, and an altitude range 


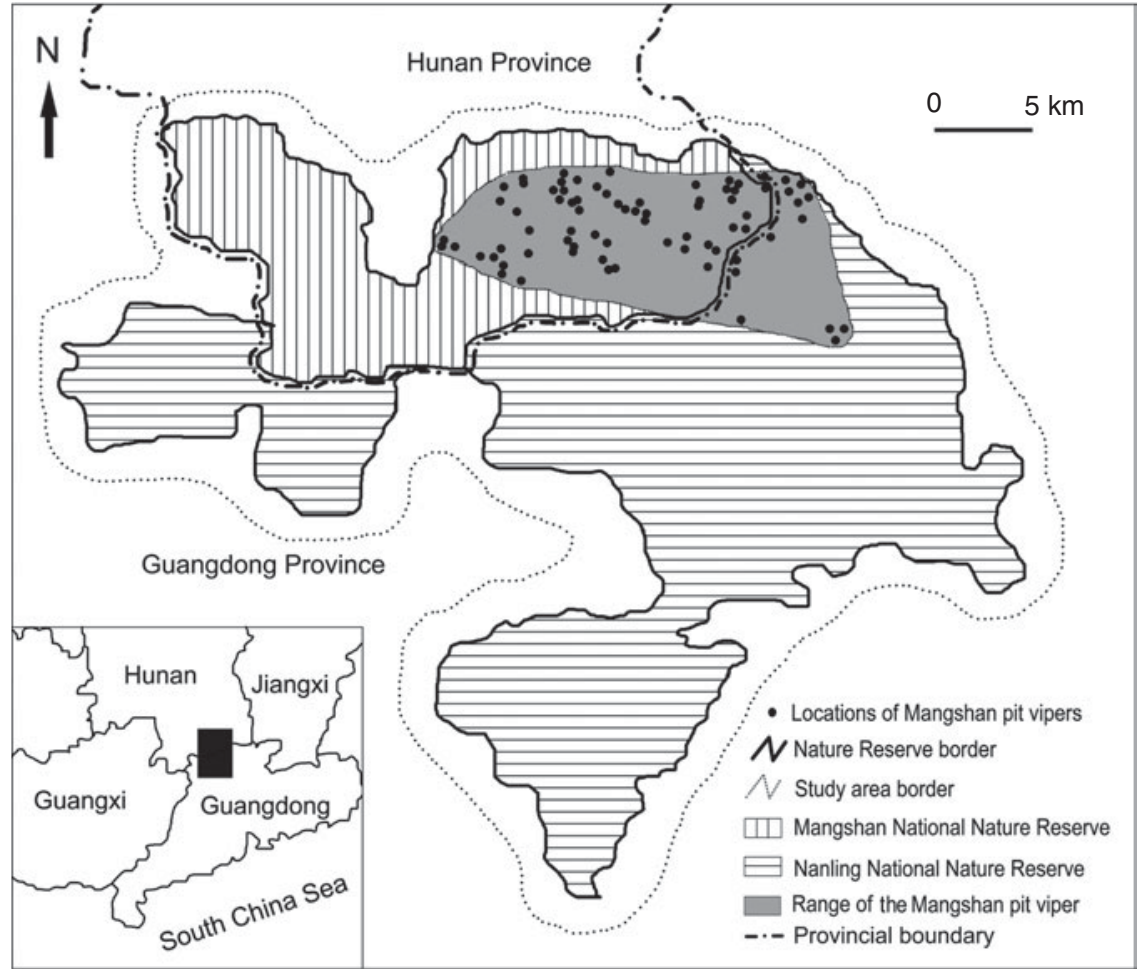

FIG. 1 Distribution of the Mangshan pit viper Protobothrops mangshanensis as indicated by presence records of the species for 1990-2010 (Table 2). The shaded rectangle on the inset indicates the location of the main map in south China.

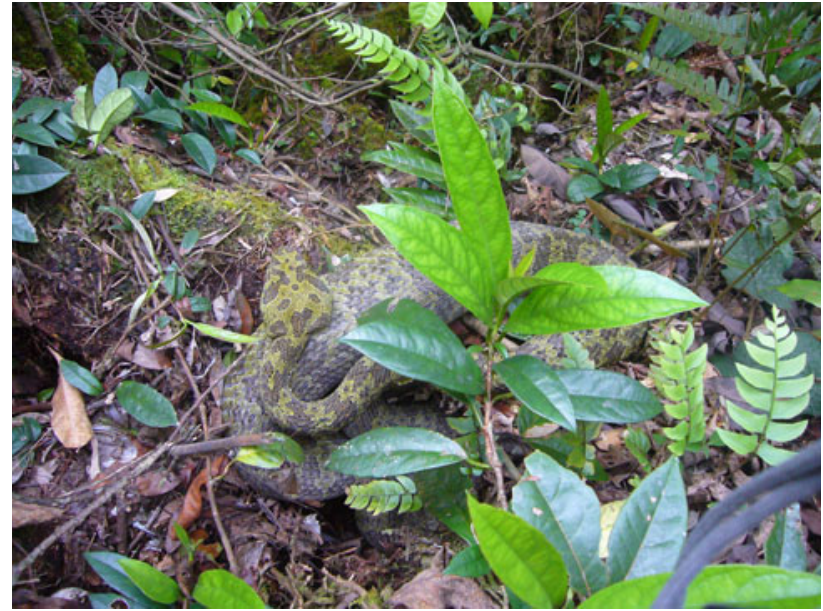

Plate 1 The Mangshan pit viper Protobothrops mangshanensis. Photograph by Yuan-hui Chen.

of $200-1,902 \mathrm{~m}$. It is located in the border areas of the provinces of Guangdong, Guangxi, Hunan and Jiangxi (Fig. 1). The temperature range is -4 to $34^{\circ} \mathrm{C}$, mean annual temperature is $17.7^{\circ} \mathrm{C}$, total annual precipitation is $1,600-$ $2,775 \mathrm{~mm}$ and the mean annual relative humidity is $84 \%$ (NNNR, 2007). The vegetation consists primarily of subtropical evergreen broad-leaved forest below 1,000 $\mathrm{m}$ and mixed coniferous and broad-leaved forest above 1,000 $\mathrm{m}$. Within the last few decades much of the forest has been destroyed by human activities and has been replaced by secondary forest (Chen, 2003).

\section{Methods}

This study consisted of three parts: a market survey, an interview survey and a field survey. Market surveys were conducted in the animal markets of seven cities around Nanling Mountain Range: Chenzhou, Yizhang, Shaoguan, Ruyuan, Lechang, Yangshan and Lianzhou. During 20072010 we visited these markets once or twice in each season (excluding winter) to gather information on the snake trade. The snake traders were often reluctant to share information with us because of fear of possible fines by wildlife officials. To gather information we therefore masqueraded as potential buyers seeking information on species, quantities, prices and origins of the snakes on display. However, it was not always possible to check snakes in the markets because large numbers of snakes were often packed into bags or cages. The Mangshan pit viper is a wellknown species with a high market price and hence any trade is relatively secret. We therefore sought help from local friends to obtain information on the species in these markets.

Informal interview surveys were conducted in c. 30 villages in and around the Nanling Mountain Range. A total of 216 local villagers were visited to gather information about the locations and numbers of Mangshan pit vipers they had observed in the wild and about threats such as habitat destruction, poaching and trade. To determine whether the species was present in the vicinity, photographs of the viper and other local and non-local snake species 
were shown to the interviewees. In addition, we interviewed the staff of local nature reserves to gather further information.

Based on the interview surveys and earlier field surveys by Chen (2002) eastern Mangshan National Nature Reserve and north-eastern Nanling National Nature Reserve were identified as the areas most likely to still support the Mangshan pit viper (Fig. 1). Based on topographical features and vegetation we searched for the viper along a total of 110 random transects at elevations of 300-1,500 m; each transect was $1-2 \mathrm{~km}$ long and $10 \mathrm{~m}$ wide. From 2007 to 2010 we spent 180 days (c. 3,000 man-hours) in field surveys during May-October (the vipers are active during these months). Each transect was walked 2-4 times, following the method of Chen (2003). Interview surveys and earlier field surveys by Chen (2002) indicated that the Mangshan pit viper is partly arboreal (generally c. 1-3 m above the ground) and mainly nocturnal. We therefore walked transects during 9.00-16.00 and with flashlights during 20.00-22.00, searching for vipers both on trees and on the ground. Locations of vipers were recorded with a global positioning system, along with information on topography, vegetation cover and composition, and distance to the nearest water source. Sex was determined by manual eversion of the hemipenes and age was estimated by body size.

To determine the species' range we gathered locality records from local villagers and guides who were familiar with the area and experienced in detecting and identifying snakes. We marked all identified sites, together with the sites documented by Chen (2002), on a digital map of the study area, using ArcView v. 3.2 (ESRI, Redlands, USA). We linked all outermost locations to form a polygon, and thus obtained an approximate estimate of the species' range.

\section{Results}

Illegal trade

We did not find any Mangshan pit vipers in the market surveys but, by talking with snake traders, we determined that the black market price is c. USD $1,000 \mathrm{~kg}^{-1}$ and that the trade is conducted secretly. The vipers are kept hidden and only when someone wants to buy and has paid a deposit will the traders agree to show the snake. Based on interviews conducted by our local friends we believe that $>30$ Mangshan pit vipers were sold during 2007-2010.

\section{Range}

Because of its distinctive morphological characters and the media coverage of the species, the viper was recognized by most interviewees. Based on the interview surveys we found
TABLE 1 Number and total length of survey transects and the number of Mangshan pit vipers Protobothrops mangshanensis found in the Nanling Mountain Range, southern China (Fig. 1), during our surveys in 2007-2010.

\begin{tabular}{|c|c|c|c|}
\hline Site & $\begin{array}{l}\text { No. of } \\
\text { transects }\end{array}$ & $\begin{array}{l}\text { Total } \\
\text { length of } \\
\text { transects } \\
(\mathrm{km})\end{array}$ & No. of vipers found \\
\hline $\begin{array}{l}\text { Mangshan } \\
\text { National } \\
\text { Nature } \\
\text { Reserve }\end{array}$ & 75 & 130 & $\begin{array}{l}7 \text { ( } 4 \text { adult females in } \\
2009,2 \text { adult females } \\
\& 1 \text { juvenile in } 2010 \text { ) }\end{array}$ \\
\hline $\begin{array}{l}\text { Nanling } \\
\text { National } \\
\text { Nature } \\
\text { Reserve }\end{array}$ & 35 & 50 & 1 juvenile in 2010 \\
\hline Total & 110 & 180 & 8 \\
\hline
\end{tabular}

TABLE 2 Records of the Mangshan pit viper in the Nanling Mountain Range during 1990-2010 (data from both interview surveys and field surveys). The totals for 2006-2010 include the data from our field surveys during 2007-2010 (Table 1).

\begin{tabular}{lllll}
\hline & \multicolumn{4}{l}{ No. of vipers } \\
\cline { 2 - 5 } Site & $1990-$ & $2001-$ & $2006-$ & \\
\hline Mangshan National & $>50$ & 12 & 10 & $>72$ \\
Nature Reserve & & & & \\
Nanling National & 7 & 6 & 8 & 21 \\
Nature Reserve & & & & \\
\hline
\end{tabular}

that the Mangshan pit viper occurs in two nature reserves (Mangshan and Nanling National Nature Reserves). A total of 88 sites were traced to the exact localities. The polygon encompassing these sites had an area of c. $105 \mathrm{~km}^{2}$ (Fig. 1): 75 and $30 \mathrm{~km}^{2}$ in Mangshan and Nanling National Nature Reserves, respectively. Our field surveys showed that the viper occurs mainly in primary evergreen broad-leaved forest and occasionally in mature secondary evergreen broad-leaved forest (naturally restored c. 30 years ago). The species were found at altitudes of 500-1,600 m, always within $<_{1} \mathrm{~km}$ and often no more than $100 \mathrm{~m}$ away from streams.

\section{Population status}

We found only eight individuals in field surveys during 2007-2010 (Table 1), of which six adult females were caught and transported to Mangshan Nature Museum for captive breeding and study (under permits from the Management Bureau of Mangshan National Nature Reserve). In our interview surveys we identified 85 historical records of the species, giving, together with the eight new records from our 
field surveys, a total of 93 records in Nanling Mountain Range during 1990-2010 (Table 2). It is difficult to find Mangshan pit vipers in the wild because of their apparently low density and cryptic colouration. A naive estimate of the density of the species can be calculated from the eight individuals that we found in $180 \mathrm{~km}$ of $10 \mathrm{~m}$ wide transects, i.e. $4.4 \mathrm{~km}^{-2}$. Extrapolating this to the $105 \mathrm{~km}^{2}$ of the apparent range of the species gives an estimate of a population of 462 .

\section{Discussion}

Based on a printed map and $>50$ historical records of the species Chen (2003) estimated that the range of the Mangshan pit viper was c. $100 \mathrm{~km}^{2}$ in the Nanling Mountain Range. Our estimate of the species' range was based on further surveys and geographical information system mapping. However, the terrain of the species' habitat is steep and hence the species' actual range may be greater than that calculated from a two-dimensional map. On the other hand, the Mangshan pit viper generally occurs in primary forest close to streams, and thus the actual area of occupancy is less than the calculated range. Chen (2003) reported that the Mangshan pit viper prefers primary forest at $700-1,100 \mathrm{~m}$ altitude. In the southern and western Mangshan National Nature Reserve such forests occur but the viper has never been found there (Chen, 2003). It is restricted to a relatively small area, despite its large size (which otherwise suggests it could range more widely) and that there are no obvious natural barriers separating it from adjacent, apparently suitable, forest habitat. It is difficult to estimate the population size of this viper accurately because of the nature of the species' habitat. Snakes in deep crevices would elude our searches, which may have led to an underestimate of density. Although no adult male snakes were found in the field, they presumably exist because we found some juveniles. Further study is required to elucidate the biology and ecology of this viper.

Our study confirms that the Mangshan pit viper is a rare species; this rarity could precipitate extinction of the species because of Allee effects (Courchamp et al., 2006). Market demand has led to over-harvesting, which is the greatest threat to the Mangshan pit viper. Based on our interview surveys it appears that zoological institutes, zoos and snake collectors in Europe, the USA, Middle East, and possibly Japan, are the major buyers of this species, and possibly some zoological institutes and zoos in China also collect this species. The Mangshan pit viper is not listed on CITES (CITES, 2010) and therefore international trade in this species is not controlled. In America, Germany and Russia, Mangshan pit vipers are kept in some zoos and institutes (Jin, 2009). San Diego Zoo, USA, has successfully bred this species in captivity (Zhao, 2006). Information from ISIS
(2011) indicates there are two Mangshan pit vipers (one male, one female) in the Moscow Zoological Park and 36 in zoos in the USA (16 males, 17 females, three of unknown sex). An unknown number are probably held by private collectors. In addition, Zoological Connections, an exporter of Chinese reptiles and amphibians based in Hong Kong (Zoological Connections, 2011), has exported Mangshan pit vipers to Europe and the USA in recent years. We do not known the origin of these individuals but we presume the exporter illegally collected them from the Nanling Mountain Range as this species does not occur in Hong Kong. As no zoos or institutes have applied for permits to obtain this species from Mangshan Nature Reserve (Yuan-hui Chen, Director of Mangshan Nature Museum, pers. comm.) we presume these snakes were smuggled out of China.

In addition to illegal harvesting, habitat destruction and degradation caused by the construction of roads and small hydro-power plants, the development of tourism also threatens the Mangshan pit viper. Although deforestation has been halted in nature reserves, illegal harvest of bamboo still occurs in Mangshan National Nature Reserve, negatively affecting the integrity of the ecosystem, reducing vegetation cover, and degrading the habitat of the Mangshan pit viper. In addition, our interview surveys suggested that people sometimes kill or catch Mangshan pit vipers when they encounter the species during bamboo harvesting. Development of the road network and increases in vehicular traffic and the number of tourists visiting the reserves also present additional risks to the snake. Mangshan pit vipers sometimes venture onto roads and may be killed by cars, as was observed by us in Mangshan National Nature Reserve in June 2010. The increasing number of tourists entering the reserves also increases the chance of people encountering this snake. In October 2007, for example, a tourist poached a small Mangshan pit viper in Mangshan National Nature Reserve (Yuan-hui Chen, Director of Mangshan Nature Museum, pers. comm.). With a population estimated at $<500$ protection of the habitat of the Mangshan pit viper is urgently required. Such protection would also extend benefits to other rare species in this region, such as the horned pit viper Protobothrops cornutus and big-headed turtle Platysternon megacephalum.

For a geographically restricted species with a small population size continuous harvesting is likely to have a negative impact on its survival and make it more susceptible to stochastic events. In recent years extreme climatic events have increased in China (Chen \& Yang, 2008). After an exceptionally severe snow storm in southern China in spring 2008 that caused prolonged freezing in Nanling Mountain Range, two dead Mangshan pit vipers, one dead Burmese python Python molurus bivittatus, and other dead animals (including birds and small mammals) were found 
in Nanling Mountain Range, during our fieldwork. Chinese conservationists have suggested listing the species as a grade I key state-protected species, to control illegal harvesting and trade (Chen, 2002, 2003). However, the Wildlife Protection Law is yet to be revised and the Mangshan pit viper is currently only designated as a terrestrial wild animal with important ecological, economic and scientific values, which is a lower protection level that does not provide effective protection against illegal harvesting and trade. Local governments and the two nature reserves are actively promoting tourism in the reserves and they need to minimize impacts of this on the Mangshan pit viper and other wildlife. Based on the results of our study we present five recommendations for conservation of the Mangshan pit viper: (1) it should be added to the list of grade I key stateprotected species and illegal activities such as harvesting, trade and habitat destruction should be halted by enhancing patrolling and law enforcement in the two Nature Reserves, (2) local governments and nature reserves should improve conservation measures to minimize the negative impact of tourism on this viper, (3) it should be listed in CITES Appendix II, to control international commercial trade in the species, (4) resources are required for studying the biology and ecology of this little-known snake and to monitor its population, to produce a strong scientific basis for designing effective conservation measures, and (5) the wild populations should be reinforced by augmentation from existing captive populations.

We have submitted our survey results and recommendations to the appropriate authorities of the State Forestry Administration and Guangdong Provincial Forestry Bureau. In June 2010 we conducted a series of educational activities to improve the awareness of local people living in the vicinity of this rare viper. Our future plans are to cooperate with local governments, universities, NGOs and the two nature reserves to initiate long-term monitoring, ecological research, and conservation of wild populations, and to develop further educational programmes that will enhance support from local people.

\section{Acknowledgements}

We thank Kai-he Lu, Xiao-dong Liang, Yue-ning Gong, Zhi-ming Chen, Lian-chao Chen, Jin-qing Liao, You-sheng Cai, Hai-jing Wang and Dong-sheng Pan for their help during fieldwork. Dr Xue-li Lu participated in fieldwork and helped to make Fig. 1. Professor Nancy E. Karraker, Markus Auer and Gui-hong Zhang helped to review the text. This study was supported financially by the Ocean Park Conservation Foundation of Hong Kong, Hunan Provincial Natural Science Foundation of China (No. 09JJ3030), the Wild Animal Conservation Fund of the State Forestry Administration of China, and the Scientific and Technological Plan Project of Guangdong Province (No. 2010B031000012). We declare that no direct financial benefits will accrue to us from this publication.

\section{References}

Chen, L.J. \& YAnG, X.H. (2008) The 'panda' of the snake cannot come to life after an exceptionally severe snow storm. Nandu Daily, 26 Feb 2008, p. A12.

Chen, Y.H. (1998) The current status of Ermia mangshanensis and conservation strategy. Sichuan Journal of Zoology, 17, 76-78.

Chen, Y.H. (2002) The results of a special survey of Mangshan pit viper (Ermia mangshanensis). Sichuan Journal of Zoology, 21, $183-184$.

Chen, Y.H. (2003) A survey of Mangshan pit viper. Journal of Snakes, $15,62-64$.

CITES (2010) CITES Appendix. Http://www.cites.org/eng/app/index. shtml [accessed 16 September 2010].

Courchamp, F., Angulo, E., Rivalan, P., Hall, R.J., Signoret, L., Bull, L. \& Meinard, Y. (2006) Rarity value and species extinction: the anthropogenic Allee effect. PLoS Biology, 4, 1-6.

Gumprecht, A. \& Tillack, F. (2004) Proposal for a replacement name of the snake genus Ermia Zhang, 1993. Russian Journal of Herpetology, 11, 73-76.

Guo, P., Malhotra, A., Li, P.P., Pook, C.E. \& Creer, S. (2007) New evidence on the phylogenetic position of the poorly known Asian pit viper Protobothrops kaulbacki (Serpentes: Viperidae: Crotalinae) with a redescription of the species and a revision of the genus Protobothrops. Herpetological Journal, 17, 237-246.

ISIS (2011) ISIS Species Holding. Https://www.isis.org/Pages/ findanimals.aspx [accessed 12 January 2011].

Jin, Y. (2009) Report on the Revival of Mangshan Little Green Dragon. Guangzhou Daily, 16 Aug 2009, p. B1.

NnNR (Nanling National Nature Reserve) (2007) Brief Introduction to Nanling National Nature Reserve. Http://www.gdnl. org/wwwroot/XXLR1.ASP?ID=78 [accessed 8 March 2012]. [In Chinese]

W AnG, S. \& XIE, Y. (2004) China Species Red List. Vol. 1. Science Press, Beijing, China.

Zнао, E.M. (1998) China Red Data Book of Endangered Animals: Amphibia and Reptilia. Science Press, Beijing, China.

ZH aо, E.M. (2006) Snakes of China (I). Anhui Science and Technology Press, Hefei, China.

Zhao, E.M. \& Chen, Y.H. (1990) Description of a new species of the genus Trimeresurus. Sichuan Journal of Zoology, 23, 11-12.

ZHANG, F.J. (1993) Division of the genus Trimeresurus (sensu lato) (Serpentes: Viperidae), based on the morphology of their skulls. In Proceedings of the First Asian Herpetology Meeting, Huangshan (eds E.M. Zhao, B.H. Chen \& T.J. Papenfuss), pp. 48-57. China Forestry Press, Beijing, China.

ZHou, Z. (2012) Protobothrops mangshanensis. In IUCN Red List of Threatened Species v. 2012.1. Http://www.iucnredlist.org [accessed 21 September 2012].

Zoological Connections (2011) Http://www.zoocon.com/herps [accessed 12 January 2011].

\section{Biographical sketches}

SHI-PING GoNG is interested in the taxonomy, behavioural ecology, and population ecology, captive breeding, trade and conservation of 
wild animals, and especially of reptiles and amphibians in China. He is also interested in reintroduction, biological invasions, biodiversity conservation policy, nature reserve management and public education for wildlife conservation. DAO-DE YANG is interested in wildlife conservation and nature reserve management, and especially the conservation of reptiles and amphibians and the reintroduction of Père David's deer in China. YUAN-Hui Chen is interested in the ecology, captive breeding, trade and conservation of snakes, and especially in the captive breeding and conservation of the Mangshan pit viper. Michael LAU is interested in ecology, trade, conservation and taxonomy of wildlife, particularly of reptiles and amphibians. Currently he is also involved waterbird conservation programmes in Hongkong. FU-MIN WANG is interested in veterinary matters, trade and rescue of wildlife in Guangdong. 